\title{
Dynamic analysis of reciprocating compressor with a translational joint clearance
}

\author{
Shouguo Cheng \\ School of Mechatronics Engineering and Automation, Shanghai University, Shanghai, China \\ Department of Mechanical and Electrical Engineering, Jiangyin Polytechnic College, Jiangyin, China \\ E-mail: chengshouguo@163.com
}

Received 15 April 2018; accepted 23 April 2018 DOI https://doi.org/10.21595/vp.2018.19914

Check for updates

Copyright $\mathbb{C} 2018$ Shouguo Cheng. This is an open access article distributed under the Creative Commons Attribution License, which permits unrestricted use, distribution, and reproduction in any medium, provided the original work is properly cited.

\begin{abstract}
Due to the relative movement between the crosshead and the guide of reciprocating compressor, there must be friction, wear and movement clearance between them. When the clearance reaches a certain value, the performance of the reciprocating compressor is seriously affected, and the safety of the equipment and operator is threatened. In this paper, the interaction relationship between the crosshead and the guide is established through the contact collision function, and the influence of the wear amount of the crosshead and the rotational speed of the crankshaft on the reciprocating compressor with the clearance is studied. The nonlinear characteristics of the system are analyzed by phase diagram and Lyapunov exponent. The results show that the crosshead motion of reciprocating compressor with a translational clearance is chaotic.
\end{abstract}

Keywords: reciprocating compressor, translational joint clearance, contact impact function, Lyapunov exponent.

\section{Introduction}

Reciprocating compressors are widely used in petrochemical industry. The crosshead is an important part of the reciprocating compressor, which connects the connecting rod and the piston rod. The crosshead is moving in a straight line inside the guide, which is thrust by the connecting rod and transform rotation motion of crankshaft into translation movement of piston, making the cylinder inhale and exhaust continuously. The structure of the crosshead is complex, and the force is varied. After the reciprocating compressor is running for a long time, the wear of the cross head is increasing, which has a great influence on the performance of the equipment.

The main movement mechanism of reciprocating compressor is crank slider mechanism, as shown in Figure 1. Many researchers have done a lot of research on mechanism dynamics for clearance. Paulo Flores has achieved great success in studying the dynamics of mechanisms with clearance. A general methodology for dynamic modeling and analysis of multibody systems with multiple clearance joints is presented [1], which considered the clearance size, input crank speed, and number of joints. A dynamic description of the dynamic description of a rigid body multibody system with a translational clearance joint is presented [2]. The four contact structures between the sliders and the guide are considered. A dynamic modeling and analysis method for a rigid body multibody system with a translational clearance joint is proposed and discussed by Flores. The method is based on a non smooth dynamic method, in which the interaction of elements that constitute a translational clearance joint is modeled by multiple frictional unilateral constraints [3]. Haiyang Zhao, et al. [4] proposed genetic algorithm to optimize the parameters of the clearance joint model and verified the effectiveness of the method with an experimental device. Imed Khemili and Lotfi Romdhane simulate and test the dynamics of a planar flexible slider crank clearance mechanism [5]. The modeling and simulation of a non smooth rigid body multibody system with friction translation joints are carried out by Wang Qi [6, 7].

The dynamic simulation of reciprocating compressor with a translational clearance joint in ADAMS is carried out in this paper. The influence of translational joint clearance size and crank 
velocity is discussed. The Lyapunov exponent phase diagram are used to discuss whether the system is in chaos or not.

\section{Reciprocating compressor model with a translational clearance joint}

The ideal reciprocating compressor motion mechanism is composed of three rotating joints and a translational joint. The mechanism model with the clearance of a translational joint is composed of three revolving pairs. The crosshead and the guide contact in different positions and collide each other. The horizontal direction is linear motion under the thrust and tension of the connecting rod. The force acting on the piston in reciprocating compressor valves, pipes, cylinders, etc. is expressed by $F_{g a s}$ of gas force [4], as shown in Fig. 1. Assuming that the crankshaft rotates at a constant speed, there are no clearances in the three revolute joints.

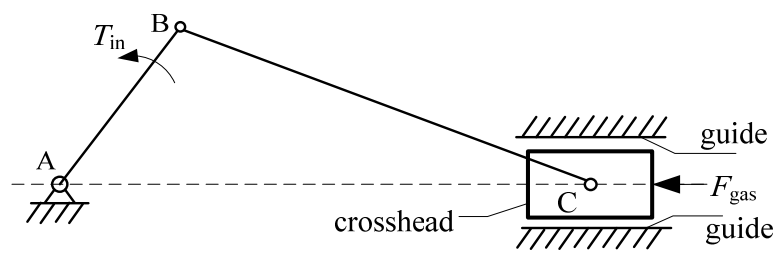

Fig. 1. schematic of reciprocating compressor with a translational clearance joint

In the process of simulation, the contact force between crosshead and slide rail is very important. In order to get closer to the real working conditions of reciprocating compressor, solid to solid contact type is selected in the simulation, and the crosshead and the guide are selected respectively for two solids. By setting parameters such as normal force, stiffness and force exponent, the ADAMS software can calculate the magnitude of contact force according to Eq. (1).

Formula of normal contact force in model:

$\left\{\begin{array}{l}F_{N}=K \delta^{n}+S T E P\left(\delta, 0,0, D_{\max }, C_{\max }\right) \dot{\delta}, \delta>0 \\ F_{N}=0, \delta \leq 0\end{array}\right.$

The local deformation of the contact region is defined as the penetration depth $(\delta: \mathrm{mm})$. The motion mechanism of reciprocating compressor for metal materials, elastic index $n=1.5$.

The instantaneous damping coefficient and penetration depth relationship in ADAMS:

$\operatorname{STEP}\left(\delta, 0,0, D_{\text {max }}, C_{\text {max }}\right)=\left\{\begin{array}{l}0, \delta \leq 0 \\ C_{\text {max }}\left(\frac{\delta}{d_{\text {max }}}\right)^{2}\left(3-2 \frac{\delta}{d_{\text {max }}}\right), 0<\delta<d_{\text {max }}, \\ C_{\text {max }}, \delta \geq d_{\text {max }}\end{array}\right.$

where, $D_{\max }$ is the penetration depth corresponding to the maximum damping coefficient $C_{\max }$, which is generally set to $0.01 \mathrm{~mm}$. Normally, the maximum damping factor $C_{\max }$ is set to $1 \%$ of the stiffness [4].

\section{Simulation results and analysis of reciprocating compressor}

Because the modeling function of ADMAS software is not flexible, the Solidworks software is used for 3D modeling, and the Parasolid format file is imported into ADAMS software. The parts of reciprocating compressor such as crank and connecting rod are regarded as rigid bodies. The rotating joint is considered as an ideal constraint. There is no translational joint between the crosshead and the guide, and the interaction force is established by the contact collision function, otherwise the crosshead will rotate with the rotation of the connecting rod. The force of the 
cylinder side is expressed by the IF function. The wear between the crosshead and the track assumes wear on the lower side, but there is a bilateral collision between the crosshead and the guide. After the system is stable, the value of two cycles is plotted into Figs. 2-5.

\subsection{Influence of the clearance}

Fig. 2(a), Fig. 2(b) and Fig. 2(c) show the relationship between the crank angle and the crosshead acceleration when the crank speed is $480 \mathrm{r} / \mathrm{min}$ and the clearance is $0.1 \mathrm{~mm}, 0.2 \mathrm{~mm}$ and $0.3 \mathrm{~mm}$, respectively. When the clearance size is different, acceleration of crosshead acceleration can be seen in Fig. 2. As can be seen from Fig. 2, the acute crosshead acceleration of the three translational joint clearance is roughly eight times (two cycles), and Fig. 2(c) is a matter of attention. When the wear amount is up to $0.3 \mathrm{~mm}$, it is necessary to deal with this dangerous situation. It is difficult to distinguish Fig. 2(a), Fig. 2(b) and Fig. 2(c) from simple observation, and other means such as signal processing are needed.

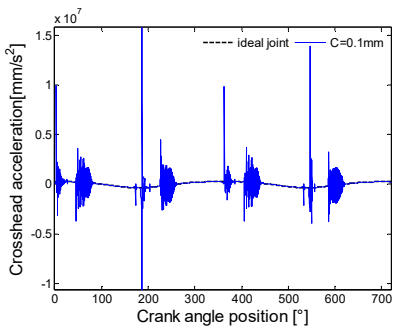

a)

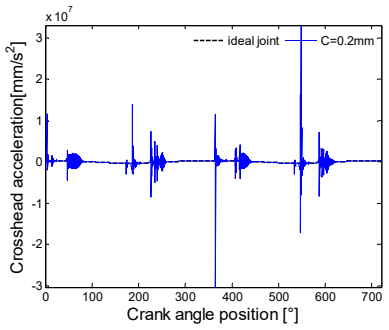

b)

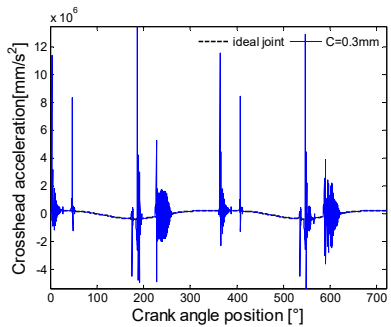

c)

Fig. 2. Acceleration of crosshead with different clearance size

\subsection{Influence of the crank speed}

Fig. 3 show the relationship between the crank angle and the crosshead acceleration when the clearance is $0.25 \mathrm{~mm}$ and the crank speeds are $360 \mathrm{r} / \mathrm{min}, 480 \mathrm{r} / \mathrm{min}$ and $600 \mathrm{r} / \mathrm{min}$, respectively. When the crank speed is different, acceleration of crosshead can be seen in Fig. 3. With the crank speed increasing, the acceleration of the crosshead is becoming shorter and shorter.

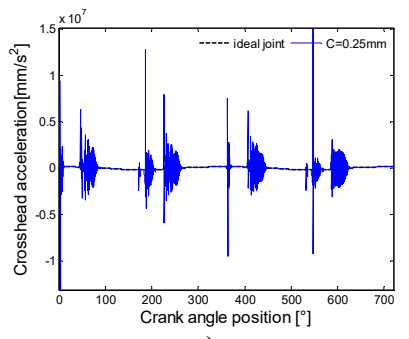

a)

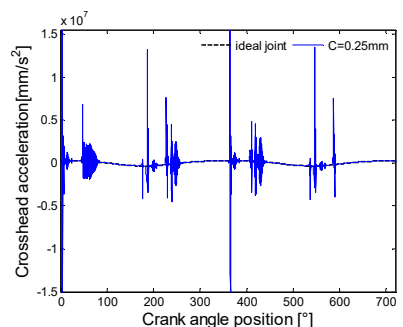

b)

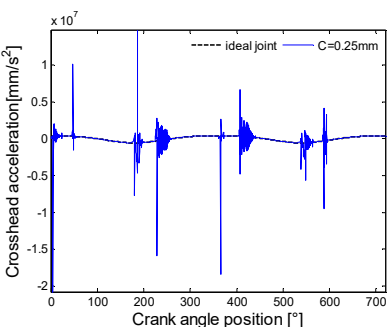

c)

Fig. 3. Acceleration of crosshead under different crank velocity

\section{Nonlinear analysis}

Joint clearance often brings obvious nonlinear characteristics to the system. Phase diagrams and Lyapunov exponent are often used as mathematical tools for qualitative study of the dynamic characteristics of nonlinear systems. It can be seen from Fig. 4 and Fig. 5 that the crosshead motion with the translational joint clearance may be chaotic.

In this paper, the wolf method is used to calculate the Lyapunov exponent. When the crank speed is $480 \mathrm{r} / \mathrm{min}$ and the clearance are $0.1 \mathrm{~mm}, 0.2 \mathrm{~mm}, 0.3 \mathrm{~mm}$, the corresponding Lyapunov exponents are $0.0565,0.0511,0.067$, and the corresponding Lyapunov exponent spectra are 
graphs Fig. 6(a-c).

When the reciprocating compressor crank speed is $360 \mathrm{r} / \mathrm{min}, 480 \mathrm{r} / \mathrm{min} 600 \mathrm{r} / \mathrm{min}$ and the clearance size is $0.25 \mathrm{~mm}$, the corresponding Lyapunov exponents are 0.0799, 0.0496, 0.0608, and the Lyapunov exponent spectra are graphs Fig. 7(a-c).

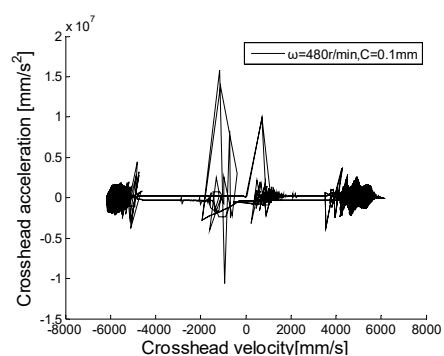

a)

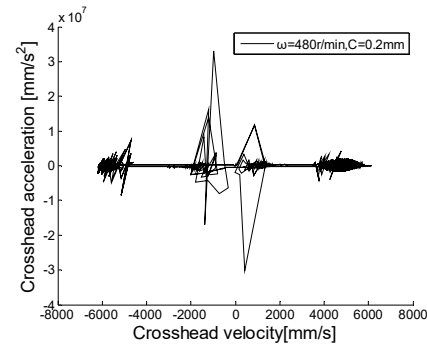

b)

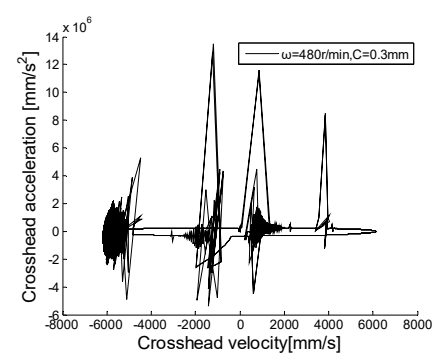

c)

Fig. 4. Acceleration of crosshead with different clearance size

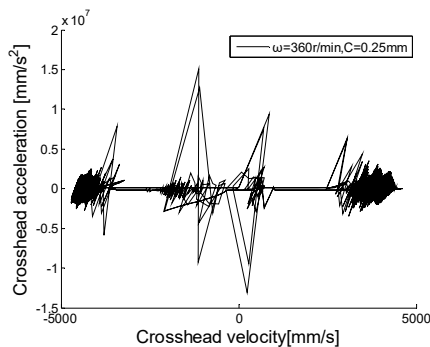

a)

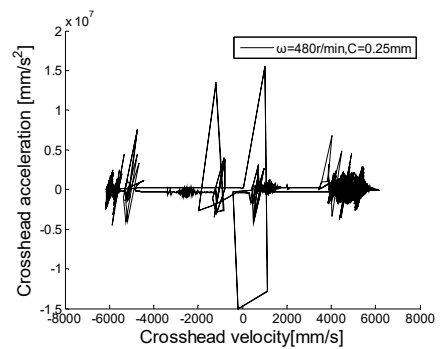

b)

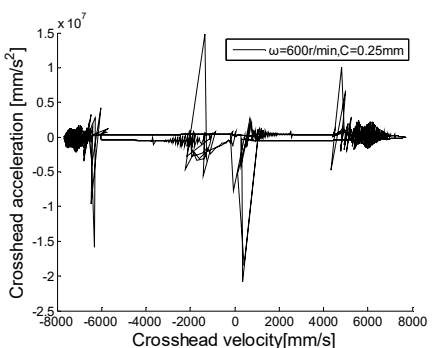

c)

Fig. 5. Acceleration of crosshead under different crank velocity

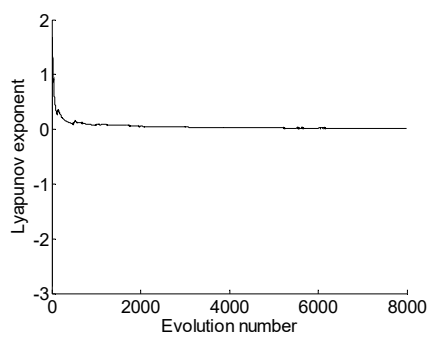

a)

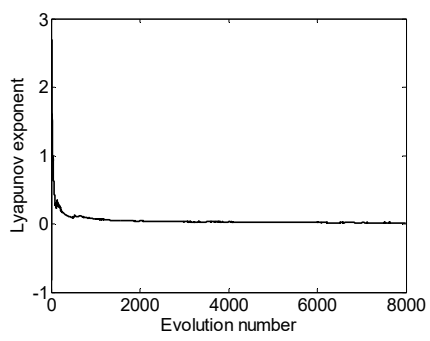

b)

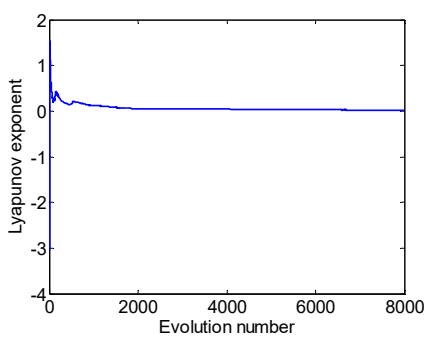

c)

Fig. 6. Lyapunov exponent spectra with different clearance size

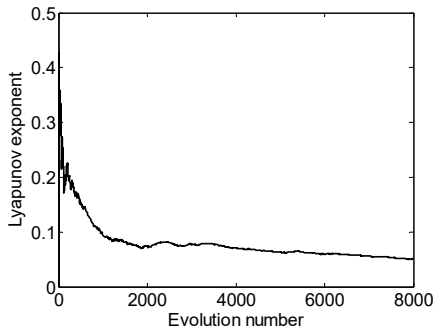

a)

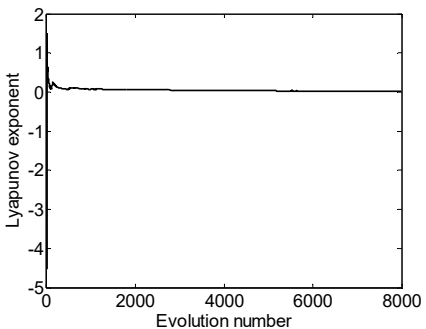

b)

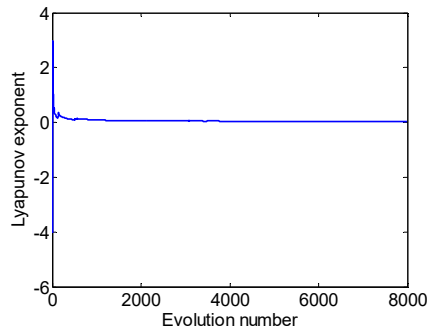

c)

Fig. 7. Lyapunov exponent spectra under different crank velocity

It can be seen that the system exhibits chaos in the case of translational joint clearance because 
all the maximum calculated Lyapunov exponent values are greater than zero.

\section{Conclusions}

The wear clearance of crosshead of reciprocating compressor is discussed in this paper. The simulation model is established by dynamics simulation software (Adams), and the interaction force between the crosshead and the guide is established by contact impact function. The influence of crank speed and clearance size on crosshead acceleration is analyzed. The nonlinear characteristics of the system are analyzed by phase diagram and Lyapunov exponent. The results show that the crosshead is worn and the system motion is chaostic. In the analysis of the impact of the size of the translational joint on the acceleration of the crosshead, a simple observation cannot be used to determine the degree of failure. The signal processing method should be used to continue the analysis of the calculation results.

\section{Acknowledgements}

This work is supported by the Natural Science Foundation of China (51575331).

\section{References}

[1] Flores Paulo. A parametric study on the dynamic response of planar multibody systems with multiple clearance joints. Nonlinear Dynamics, Vol. 61, 2010, p. 633-653.

[2] Flores P., Ambrósio J., Claro J. C. P., et al. Translational joints with clearance in rigid multibody systems. Journal of Computational and Nonlinear Dynamics, Vol. 3, Issue 1, 2008, p. 112-113.

[3] Flores Paulo, Leine Remco, Glocker Christoph. Modeling and analysis of planar rigid multibody systems with translational clearance joints based on the non-smooth dynamics approach. Multibody System Dynamics, Vol. 23, 2010, p. 165-190.

[4] Zhao Haiyang, Xu Minqiang. A parameters optimization method for planar joint clearance model and its application for dynamics simulation of reciprocating compressor. Journal of Sound and Vibration, Vol. 344, 2015, p. 416-433.

[5] Imed Khemili, Lotfi Romdhane. Dynamic analysis of a flexible slide-crank mechanism with clearance. European Journal of Mechanics - A/Solids, Vol. 27, 2008, p. 882-898.

[6] Zhang J., Wang Q. Modeling and simulation of a frictional translational joint with a flexible slider and clearance. Multibody System Dynamics, Vol. 38, Issue 4, 2016, p. 367-389.

[7] Zhuang Fangfang, Wang Qi. Modeling and simulation of the nonsmooth planar rigid multibody systems, with frictional translational joints. Multibody System Dynamics, Vol. 29, Issue 4, 2013, p. $403-423$. 